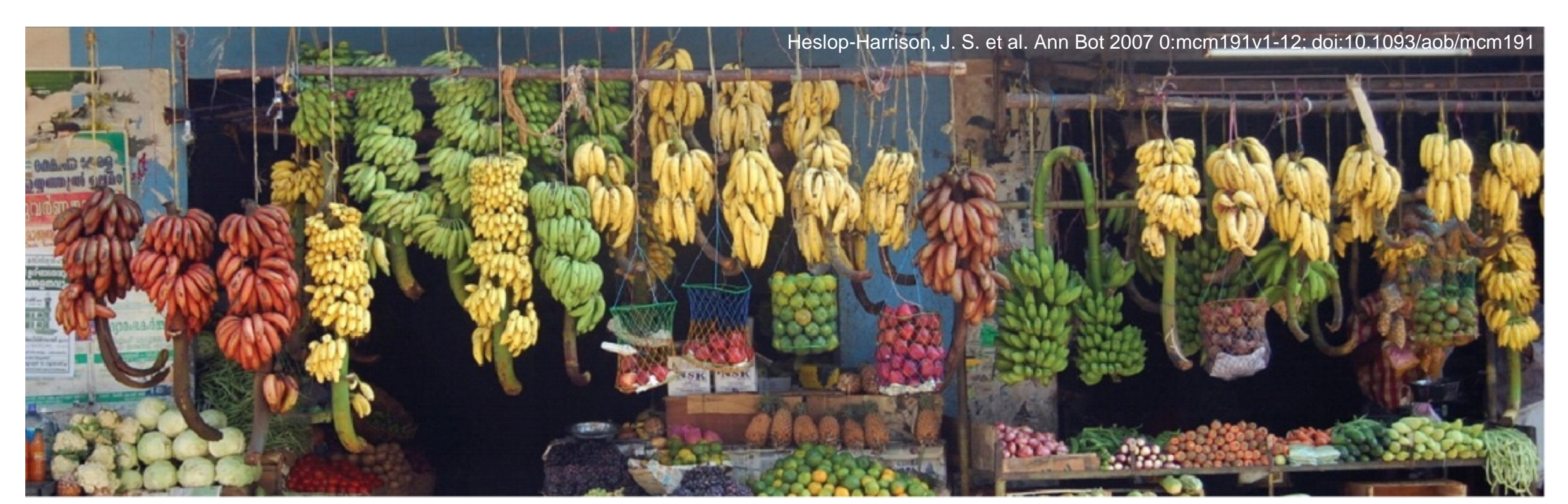

\title{
Advances in Genomics: application to banana breeding
}

Bakry F. \& Horry J.P.

Cirad (agap 


\section{Current cropping system}

Narrow genetic diversity in edible triploids

\section{(AAA, AAB, ABB)}

\section{Fragile:}

- diseases

- climate changes

- access to inputs

Markets:

- popular

fruit/vegetable

- world production $\nearrow$

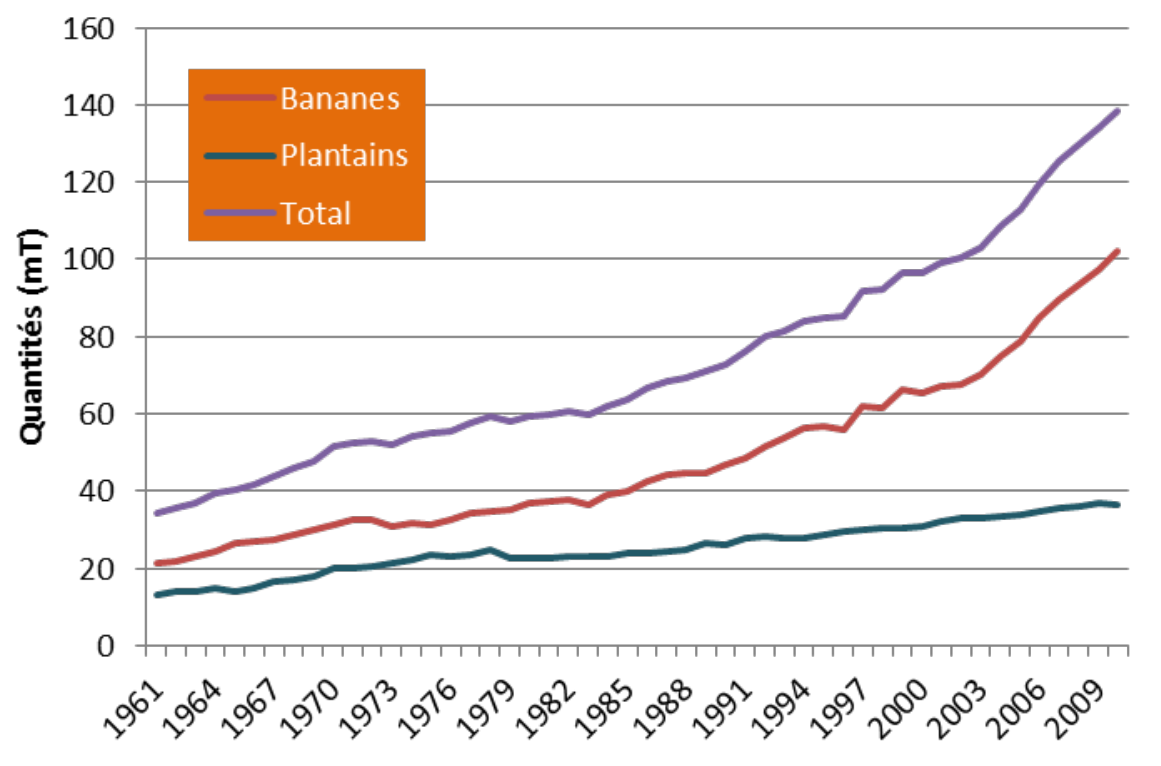




\section{Objectives for Banana Breeding}

Resistant varieties close to natural varieties

- Cercosporiosis, FOCs, in priority

- Same attributes of quality and phenology

- Productivity: equivalent or higher

- Reduced production costs

$\rightarrow$ agronomical and economical sustainability

Demand for new Musa products?

- Unknown fresh fruits/legumes

- Processing

- Varietal mix 


\section{Principles of Banana Breeding (1/3)}

Principal landraces/main features:

- Edibility (seedless, parthenocarpy)

- Triploidy

- Highly heterozygous (sub- \& interspecificity)

- Vegetatively propagated 


\section{Principles of Banana Breeding (2/3)}

Constraints to breeding :

- High gamete sterility

- Strong gamete desequilibrium

- Little knowledge on genetics and heredity

- Few recombination events

- New hybrids: primeval products 


\section{Principles of Banana Breeding (3/3)}

"Reconstructive breeding "

for dessert banana (CIRAD)

- Synthesis of triploids from diploid germplasm

- Based on Musa evolution knowledge

- Maximizing heterozygosity

- Crosses between edible varieties and disease resistant fertile clones

- Parental combinations evaluated on progenies 


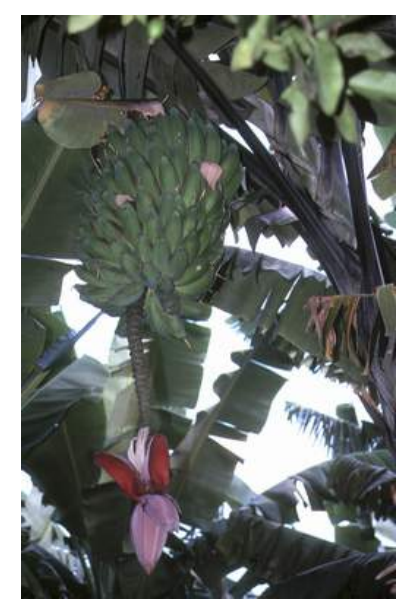

Musa balbisiana
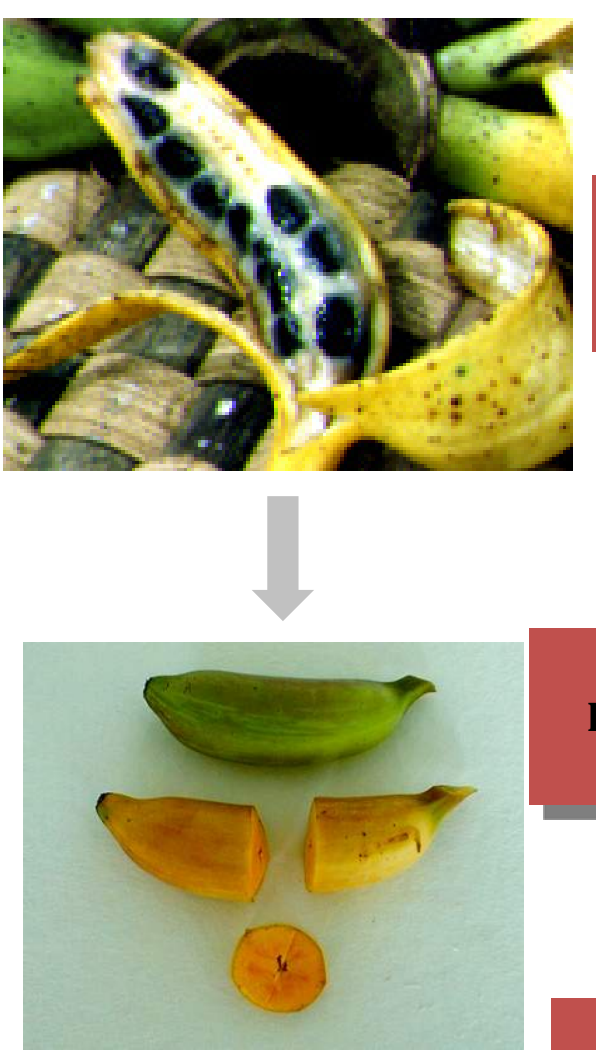

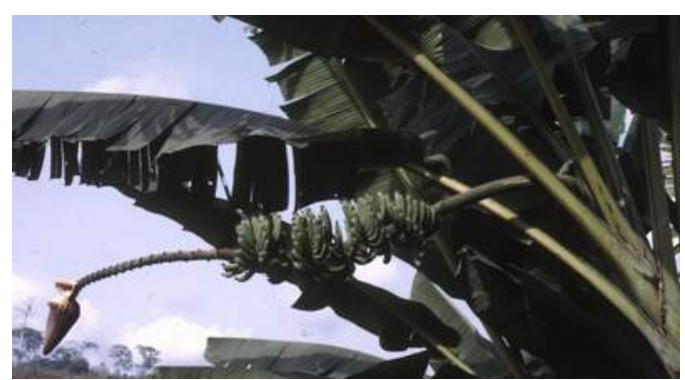

Musa acuminata

microcarpa

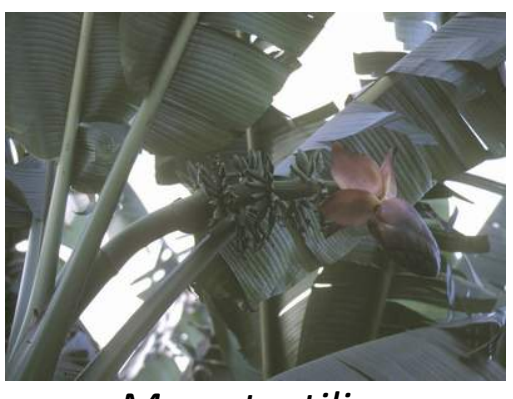

Musa textilis

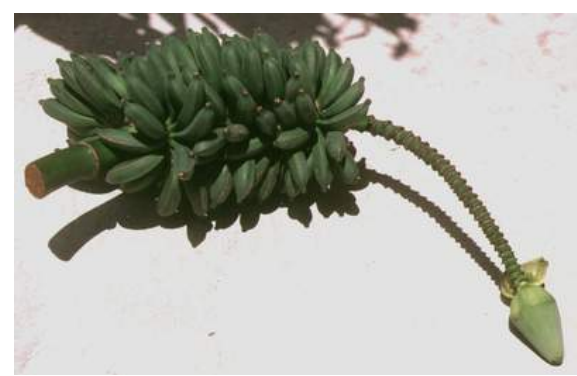

Musa schizocarpa

Evolution and domestication of bananas

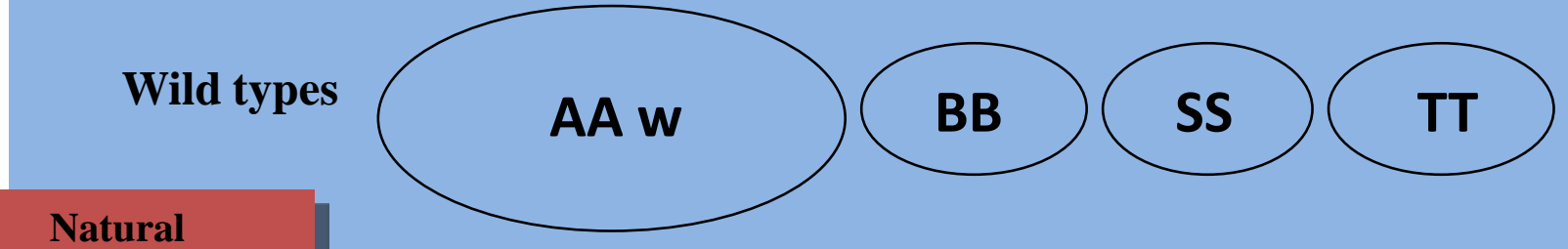

hybridization \& selection

Intra-subspecific and interspecific crosses Domestication for parthenocarpy and stérility

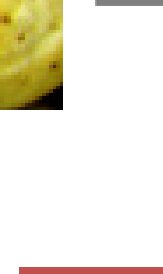

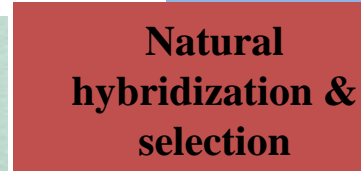

E dible diploids

hybridization \&

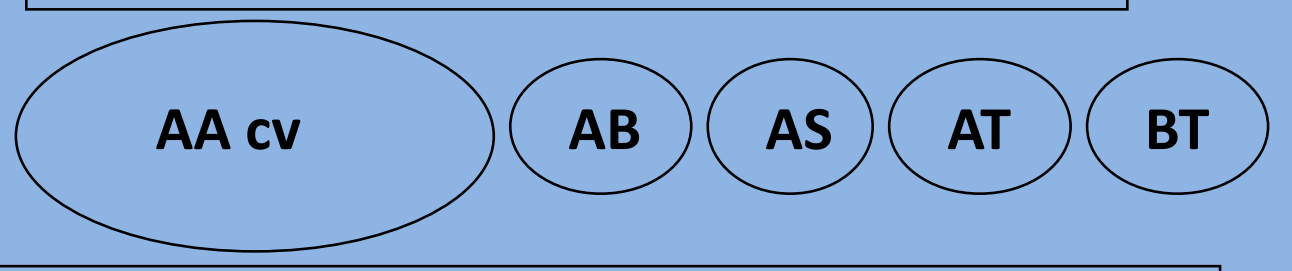

Production of $\mathrm{N}$ and $2 \mathrm{~N}$ gametes

Crosses between edible diploids and wilds or ED/ED
Triploid landraces
AAA

AAB ABB AAS 


\section{Banana evolution}

fixation and selection by vegetative propagation

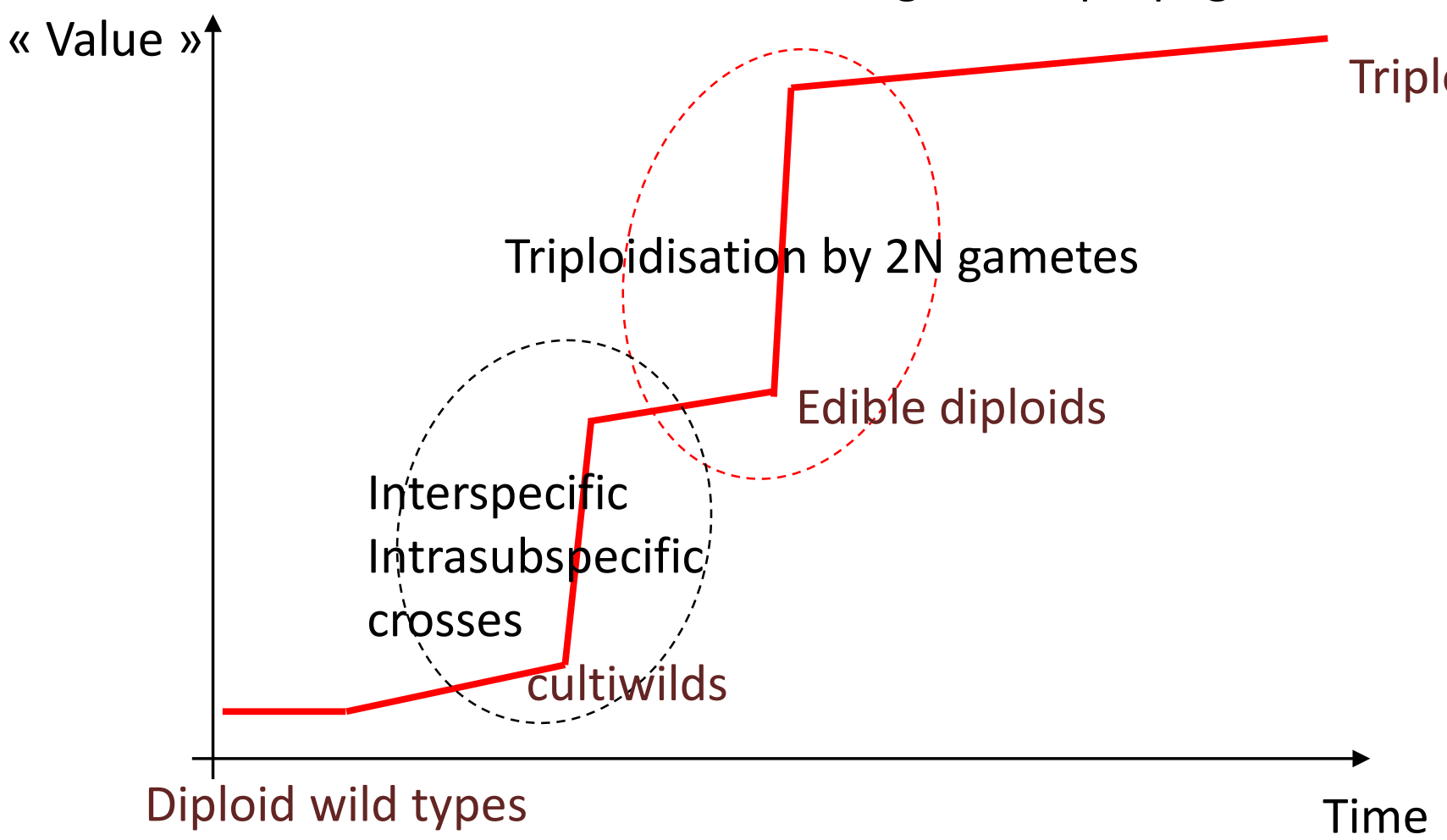

From: X. Perrier, 2013 


\section{Evolutionary history of banana}

\section{The first sub-speciations}

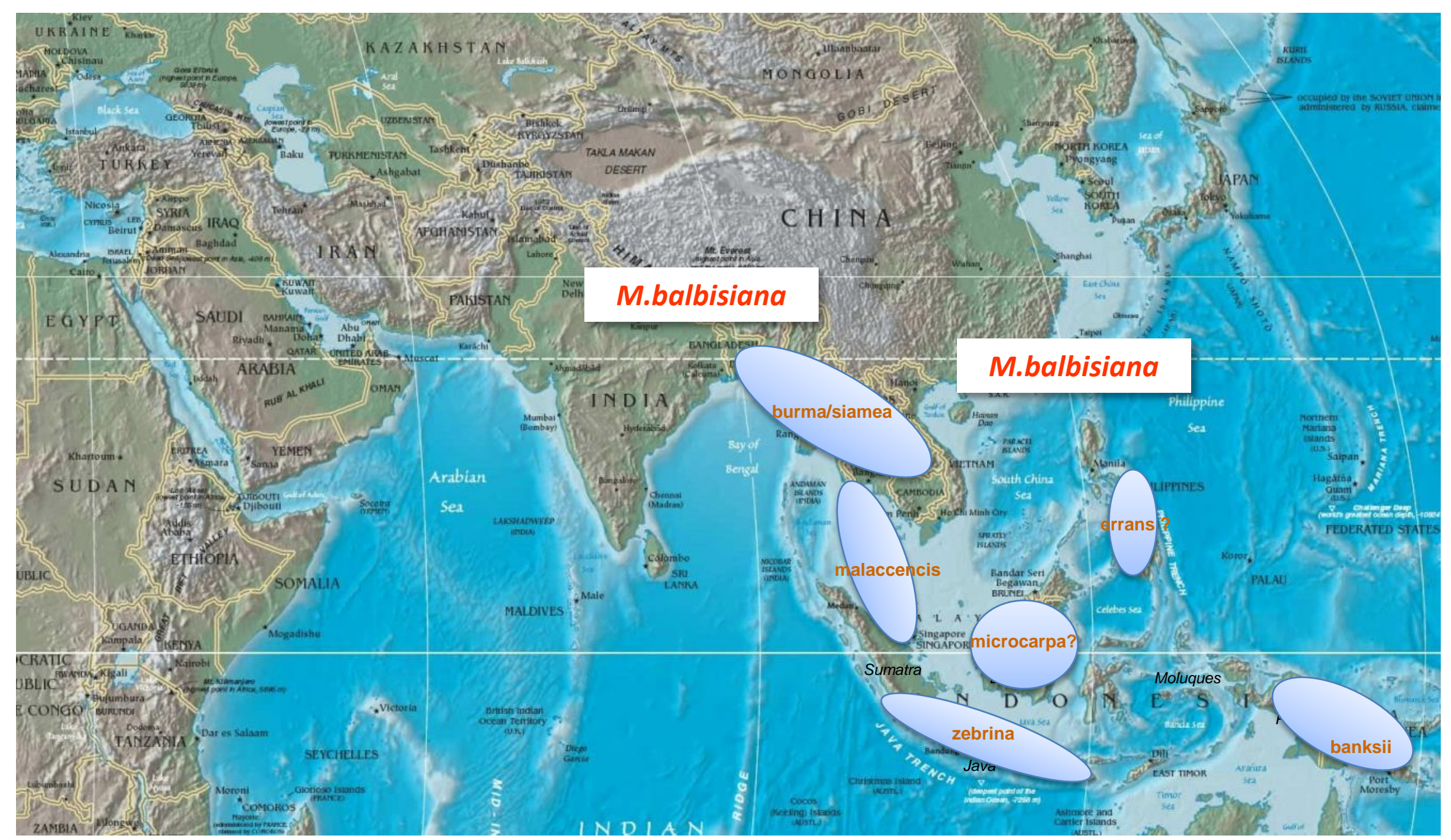

cirad (agap 


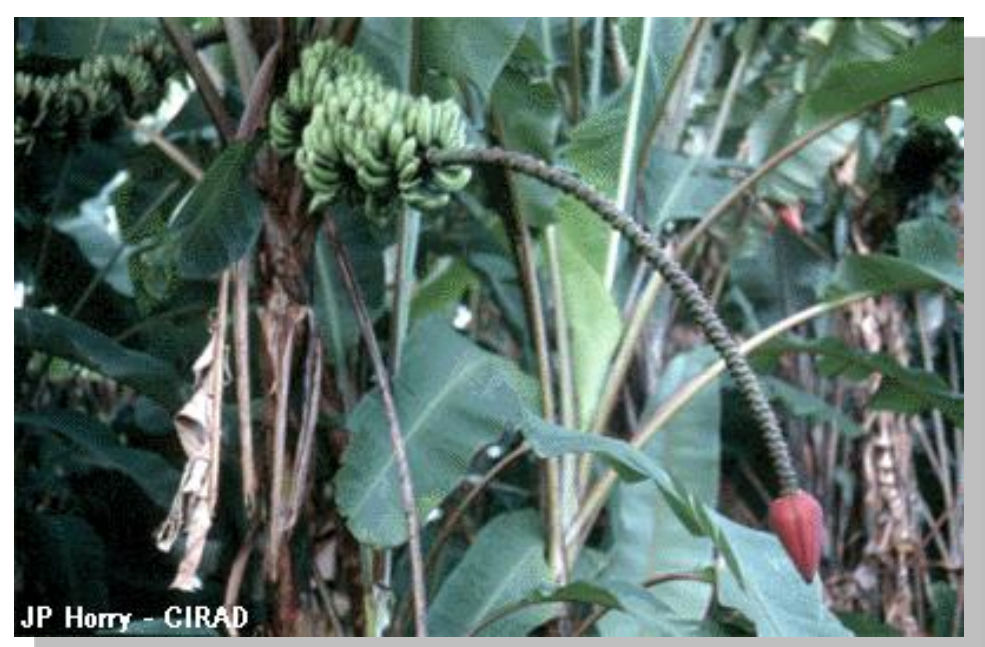

Wild : M. acuminata malaccensis (AA), 2X, Malaysia

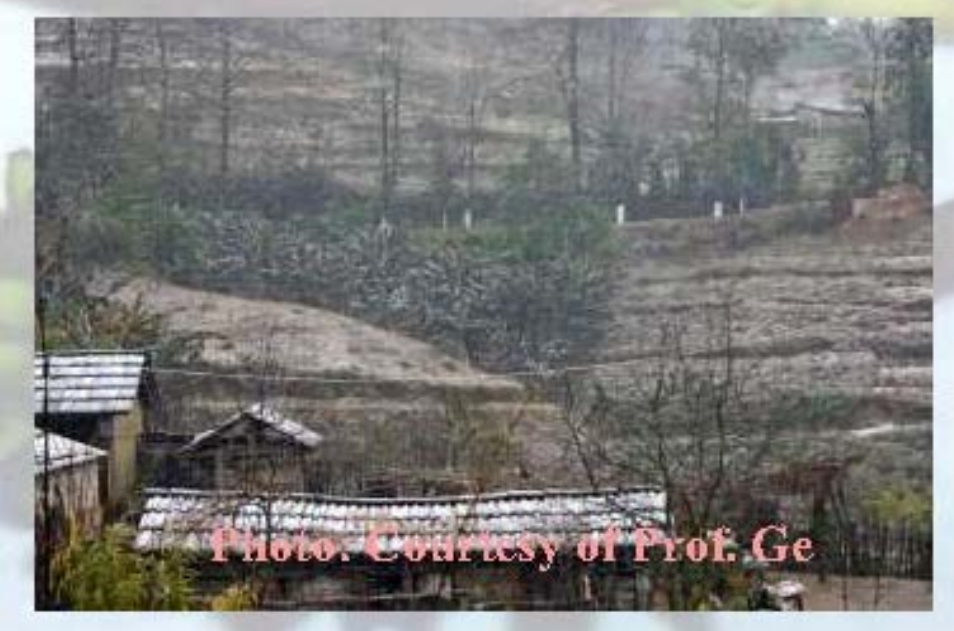

Cultiwild: M. Yunnanensis (YY), 2X, Yunnan, China (M. Hakkinen et al.)

\section{Structure software 22 SSRs/39 AAw}

$K=4$

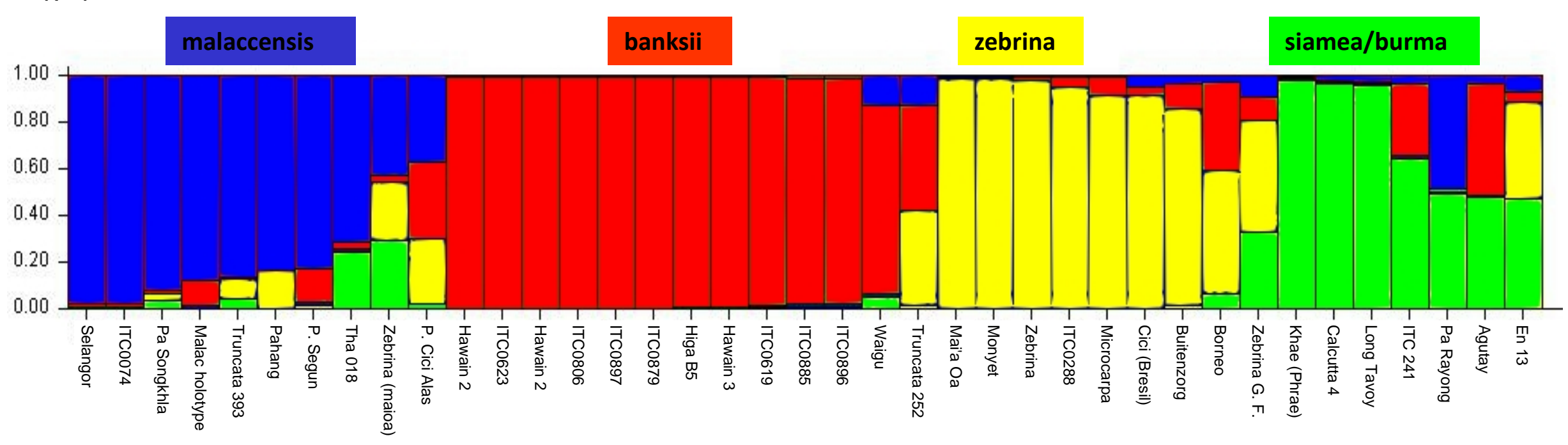




\section{Austronesian migrations vectors of domestication}

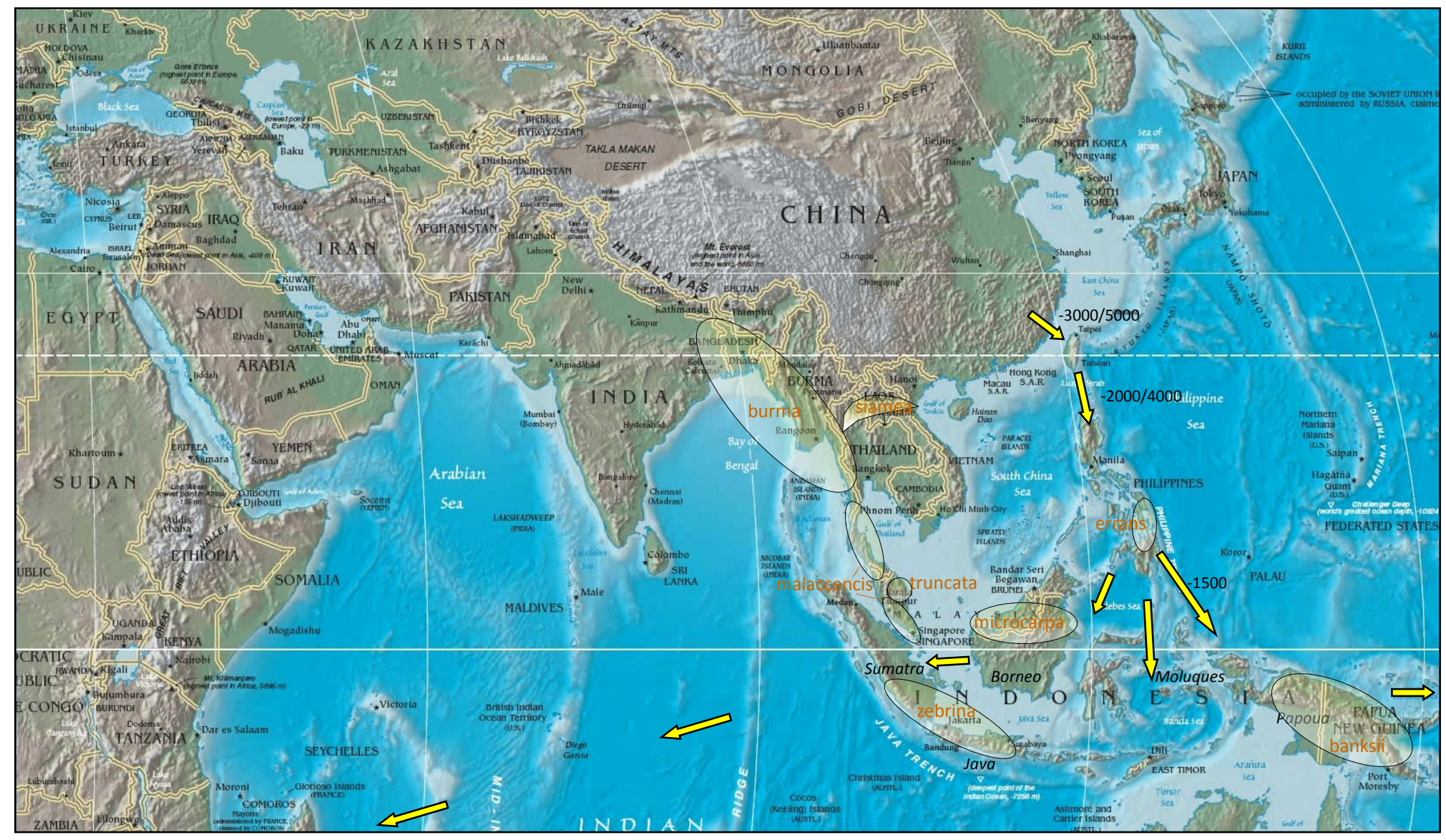




\section{Evolutionary history of banana}

Diffusion and hybridizations in contact areas

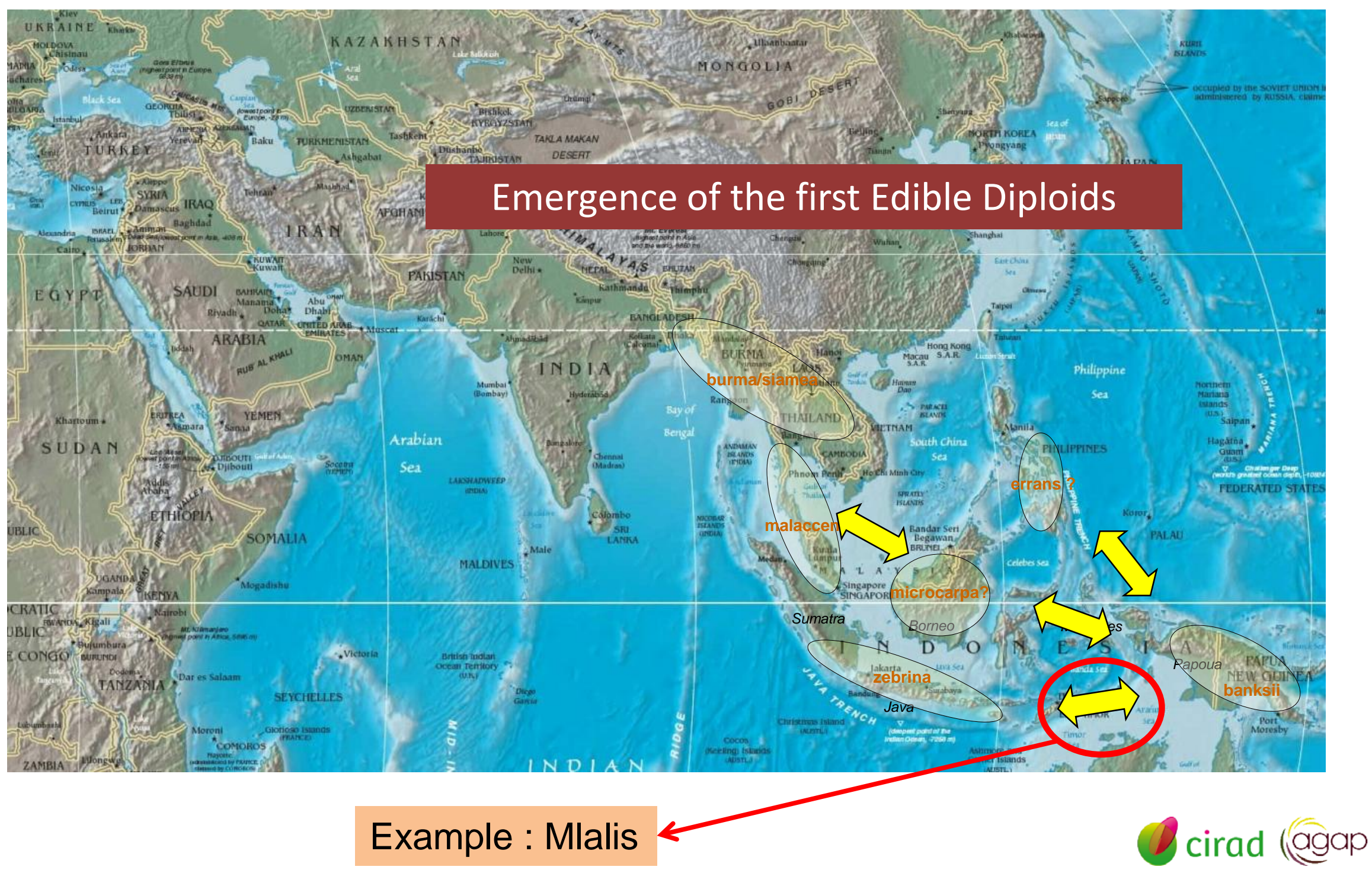


reticulated NJTree

22 SSR

172 AA w and cV

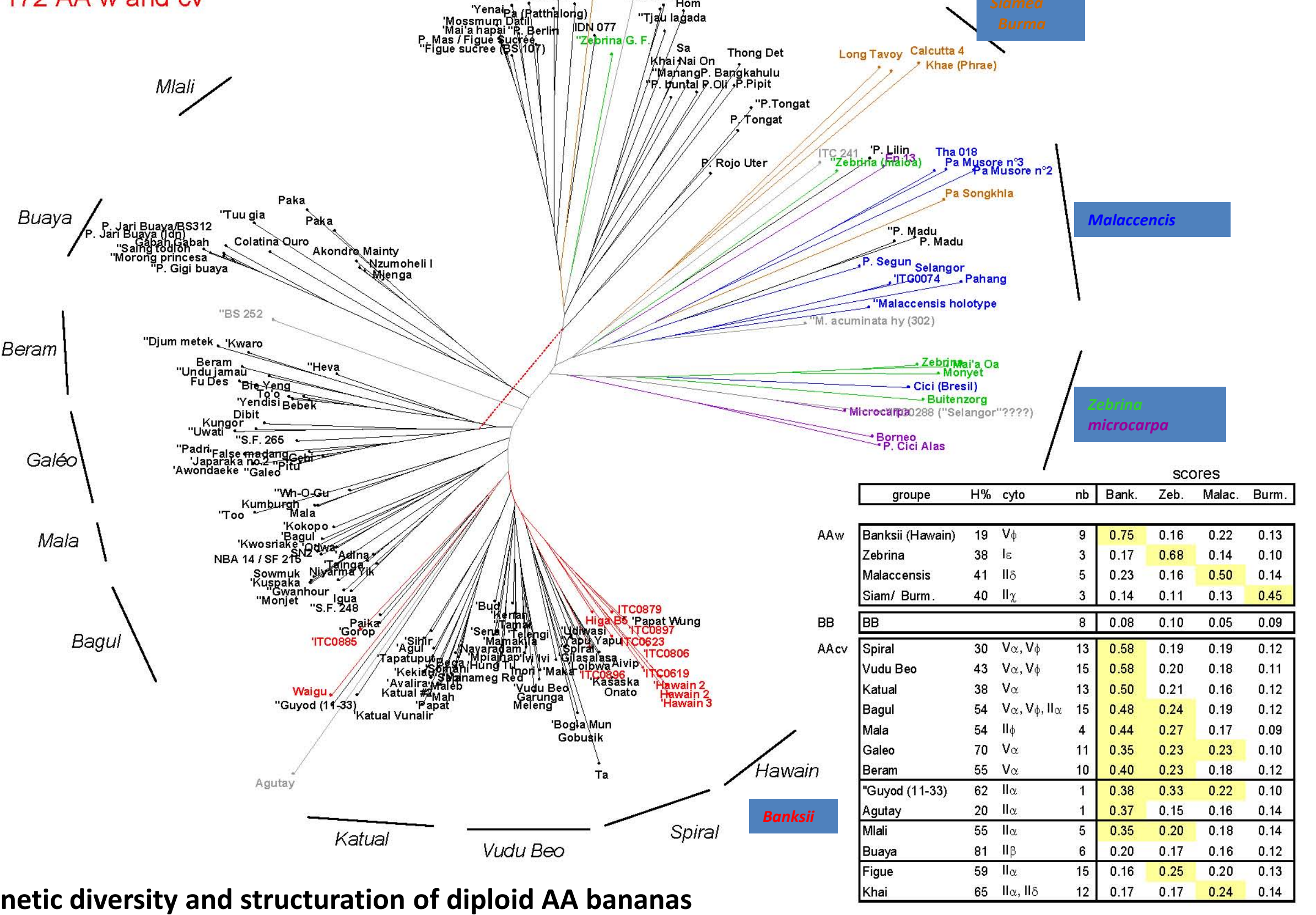

\section{Genetic diversity and structuration of diploid AA bananas}


Deciphering the genome-wide mosaic structure of chromosomes Multilocus haplotyping for CWR/ED

-Haplotypic analysis of amplicons

- Numerous amplified sites

- Numerous génotypes

- Parallele sequencing

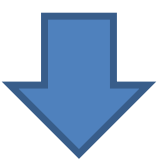

Phylogenetic assignements to segments of chromosomes

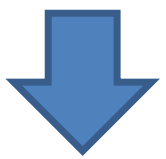

Phylogenetic reconstruction of chromosomes by genotyping for CWR and ED

\section{Questions:}

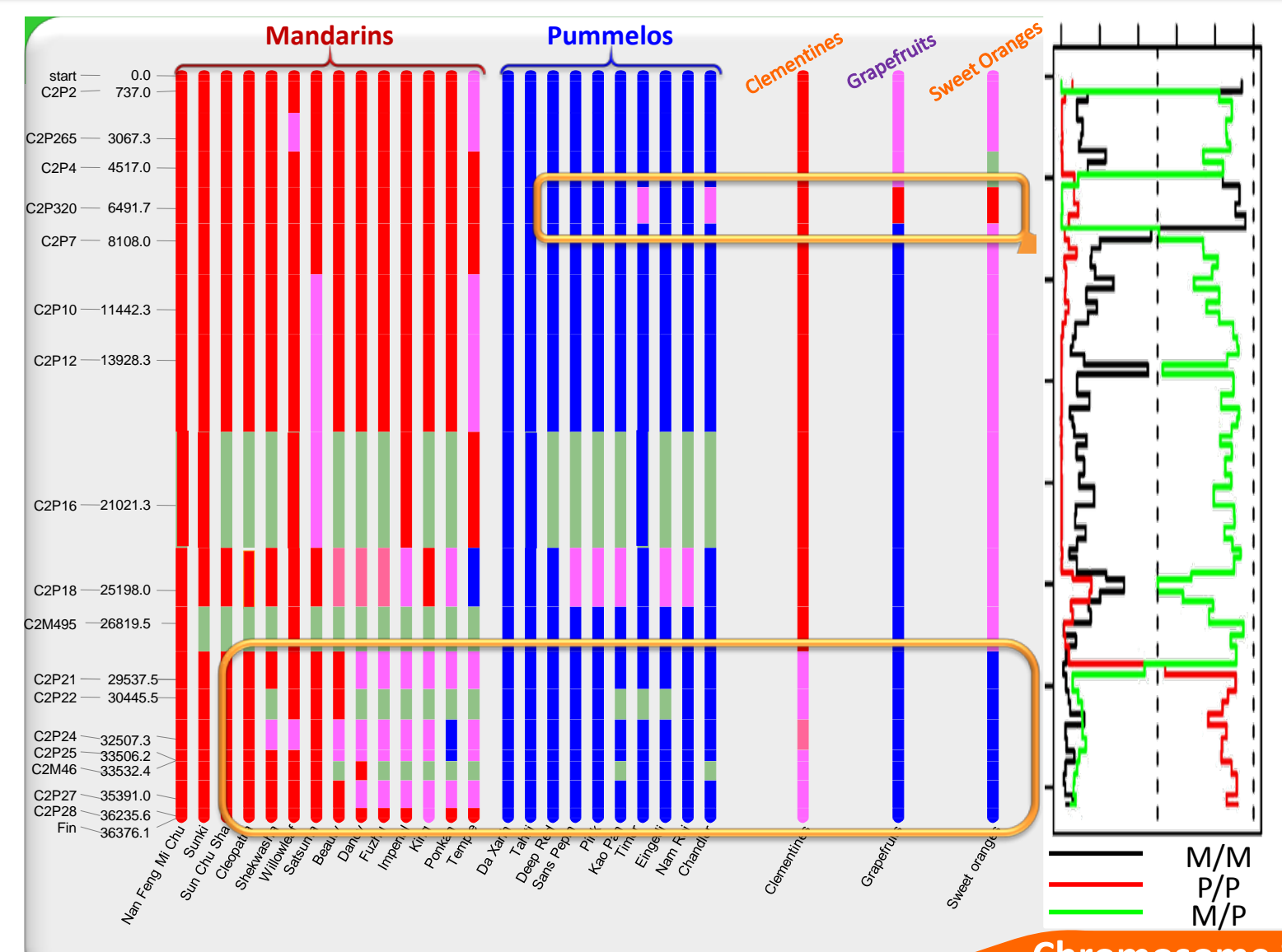

Chromosome 2

a Genome mosaics?

Curk et al., 2012. International Citrus Congress Valencia

a How many recombination cycles between CWR and ED?

a Evidences for high linkage desequilibrium ? 


\section{Reconstructive breeding in Musa}

\begin{tabular}{|c|c|c|c|c|c|}
\hline AAw & $\mathrm{x}$ & AACV & \multicolumn{3}{|c|}{ chromosome doubling (colchicine) } \\
\hline & & & AACV & & AAAACV '(1) \\
\hline AAcV & $\mathrm{x}$ & AACV & & & \\
\hline & & & chrc & mosome doubling (cc & \\
\hline AACV & $\mathrm{x}$ & BB & ABCV & 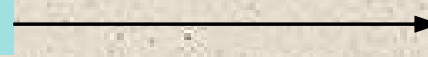 & AABBCV \\
\hline
\end{tabular}

Synthesis of triploid hybrids

AA $\quad X \quad$ AAAACV

B B $\quad \mathrm{X} \quad$ AAAACV

AA

BB

\section{$x$ \\ AABBCV}

$A A B B C V$

\section{Selections}

AAACV $(3,7)$

FLHORBANs \& CIRAD 925

$\operatorname{AABCV}(3,5)$

IRFA909, IRFA910, IRFA914

AABCV $(3,4)$

CIRADBAN L9, CIRADBAN X17

ABBCV

Under selection

Key : cv = cultivar ; $w$ = wild species ; $(1)=$ wide range of doubled-diploids; $(2)=$ neo-allotetraploid (ex: Kunnan T)

(3) = from 200 to 500 individuals by progeny; "L9" selected from this cross

(4) $=98 \%$ of the progeny are triploid ; (5) = IRFA 909, 910 \& 914 were selected from this cross 


\section{Natural occurrence of triploids}

(main hypothesis: direct pathway)

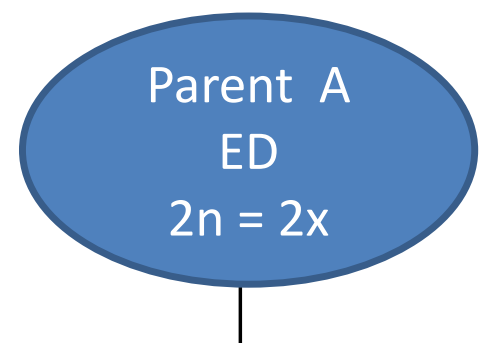

No reduction (FDR/SDR ?)
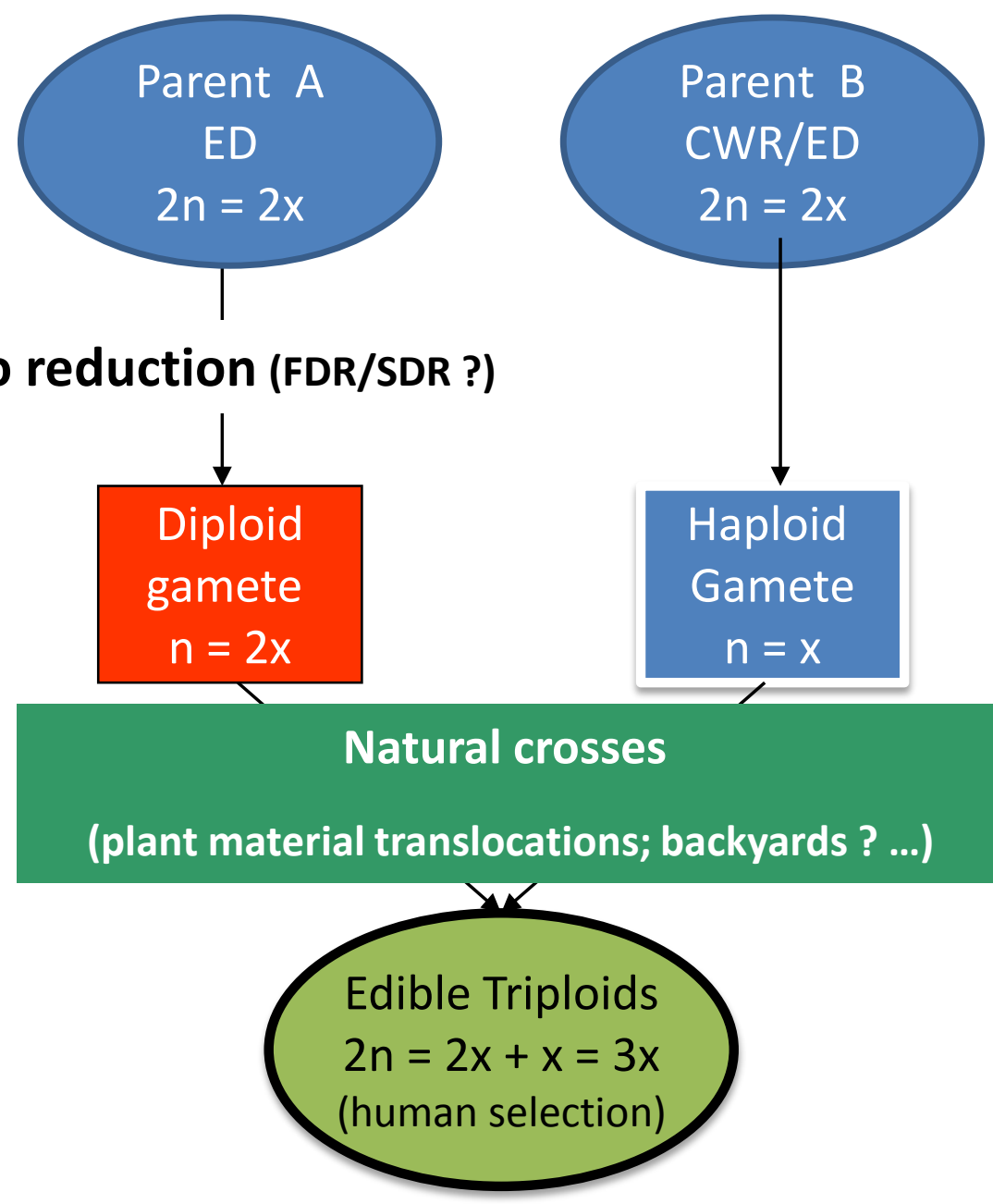

Natural crosses

(plant material translocations; backyards ? ...)

NB: Some rare indirect pathways of triploid synthesis may have occured 


\section{Diploid ancestors of triploid export bananas}

22 SSR/131 AA cV

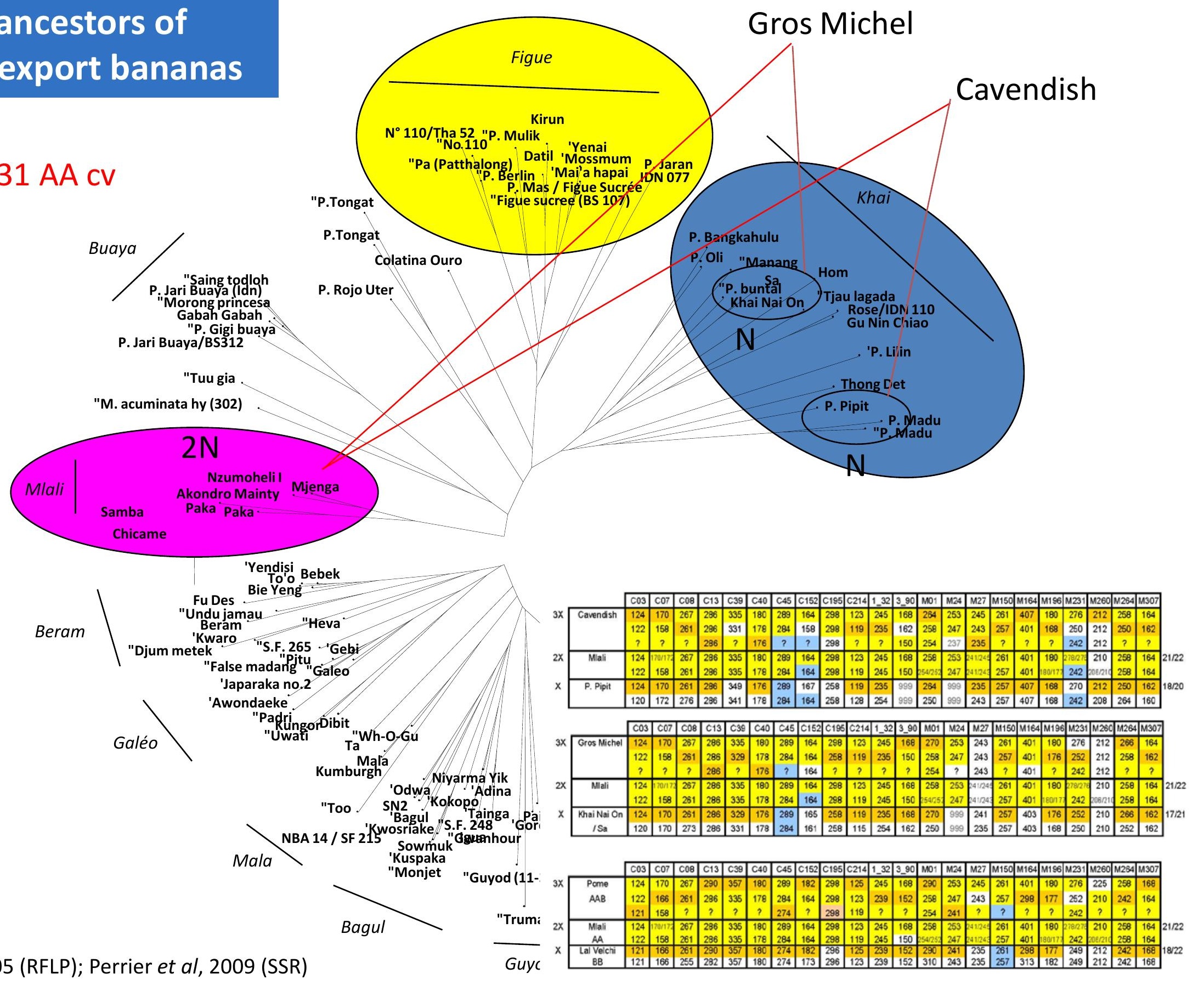




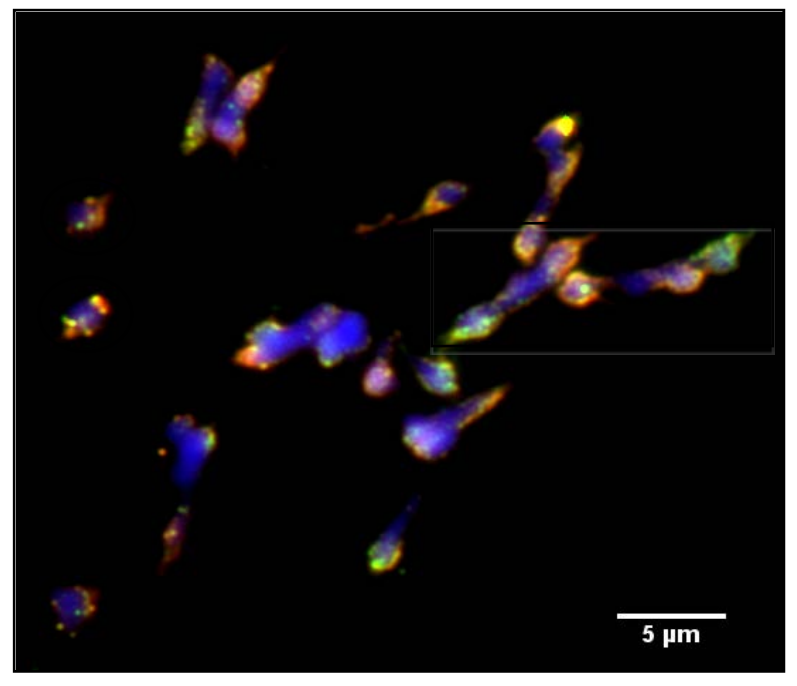

acuminata/bal bisiana chromosome pairing in interspecific varieties (GISH)

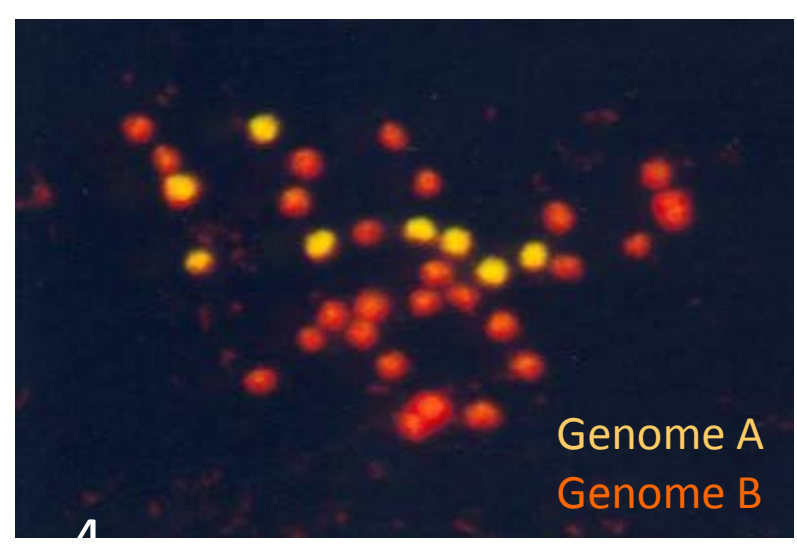

Pelipita - ABB (GISH):

8 A chromosomes; 25 B chromosomes 


\section{Heterozygocity transmission by $2 x$ gametes}

For banana breeding:
Parental heterozygocity
and pathways of $2 x$ gamete
formation are two key
points of the genetic
structure of triploid
progenies.
How to maximize
heterozygocity in triploid
progenies ?

$\%$ of parental heterozygocity transmitted to $2 x$ gametes

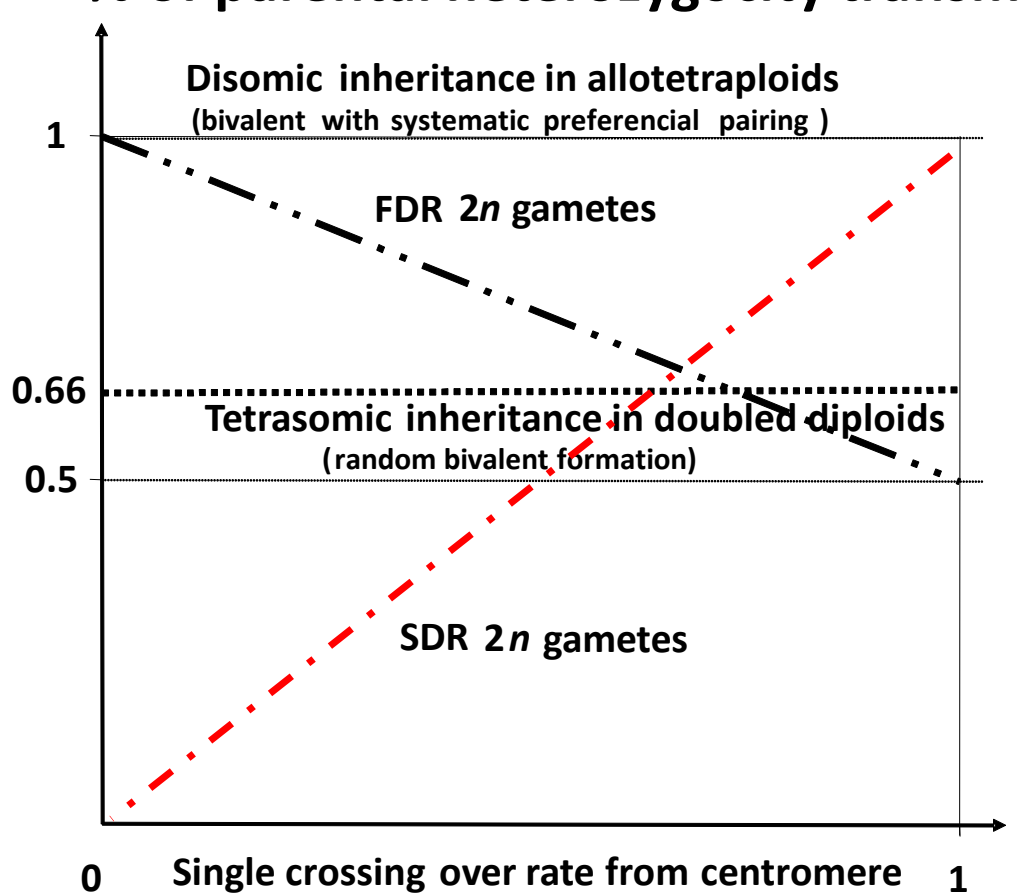




\section{Genetical and physical maps}
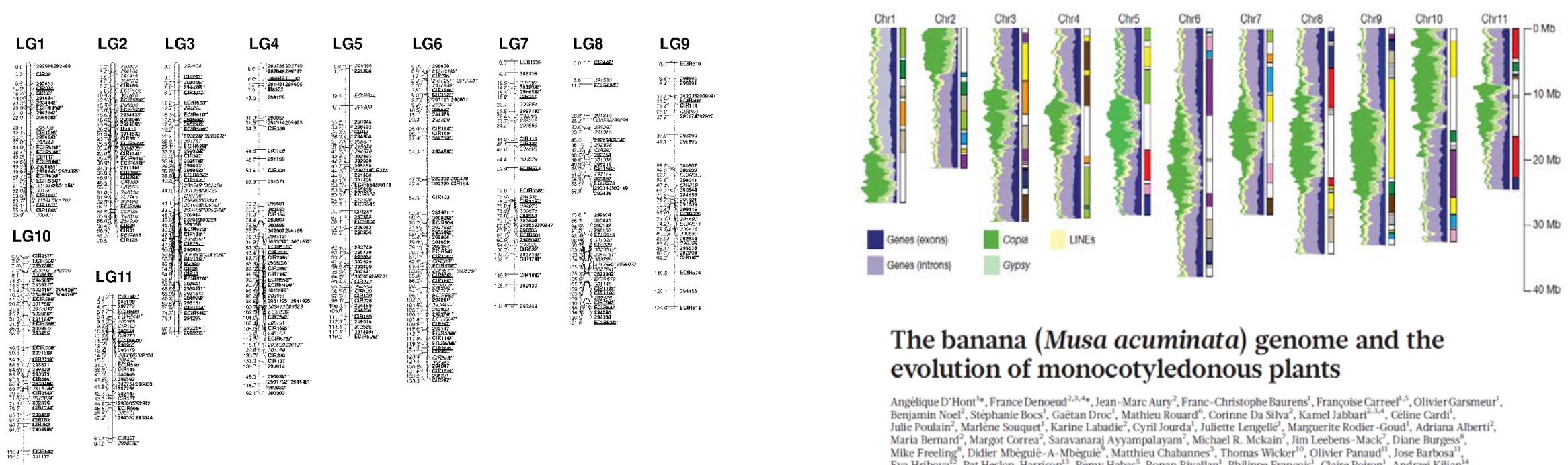

The banana (Musa acuminata) genome and the evolution of monocotyledonous plants

A saturated SSR/DArT linkage map of Musa acuminata addressing genome rearrangements among bananas

Hippolyte et al. BMC Plont Biology 2010, 10:65 http://www.biomedcentral.com/1471-2229/10/65

\section{Evidence for high segregating distortions by gamete abortion} (lethal genes, structural rearrangements) and aneuploidy Genomics opens the floor to:

- detailed genetic structure of $X$ and $2 X$ recombined gametes and patterns of inheritance

- detailed QTL and association mapping analysis (disease ressitance, quality traits, ...)

- early genomic selection (allele constitution, etc...) : fine tuning 


\section{Breeding for AAA hybrids}

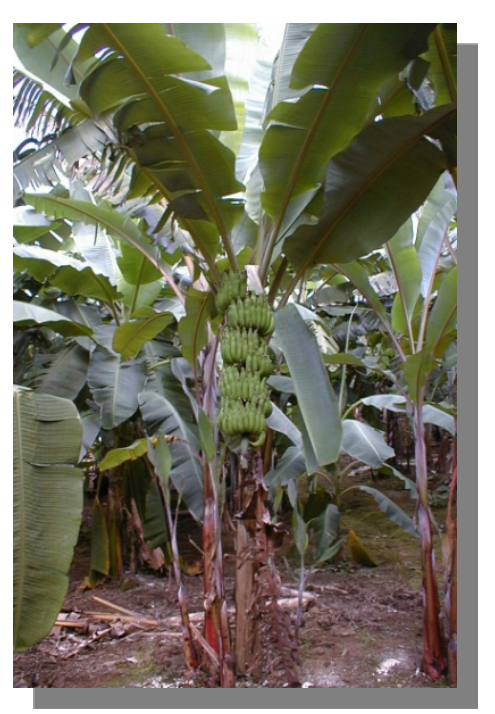

CV Rose, $\mathbf{2 X}$

- 99,5\% of triploids: (32 to 34 chromosomes)

- Parthenocarpic and no parthenocarpic hybrids

-Mean value of the family tested over 30 individuals

-Selection over 200 individuals

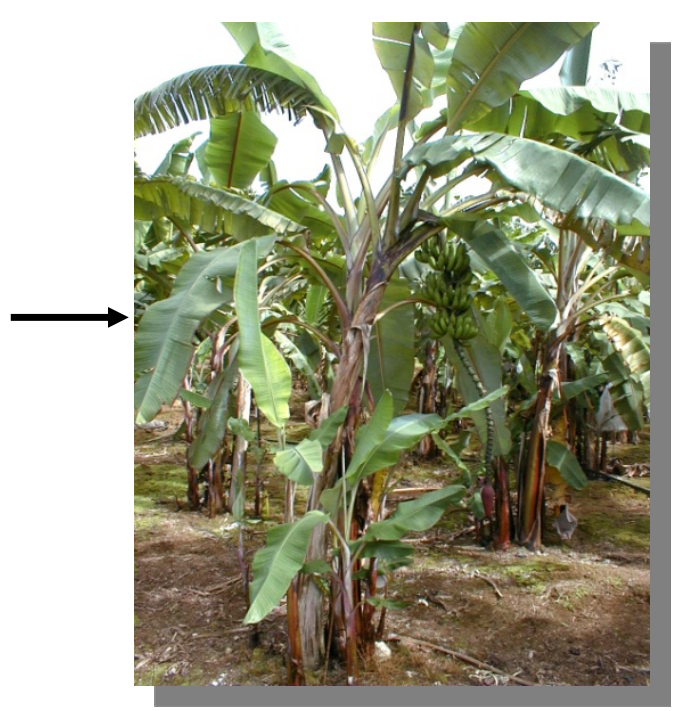

CV Rose, 4X (male)

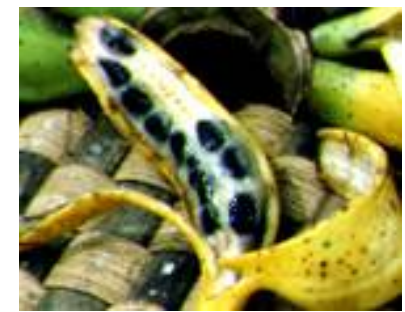

Seedy banana

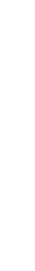




\section{Heterozygosity and cross potential}

\section{in AAA hybrid families}

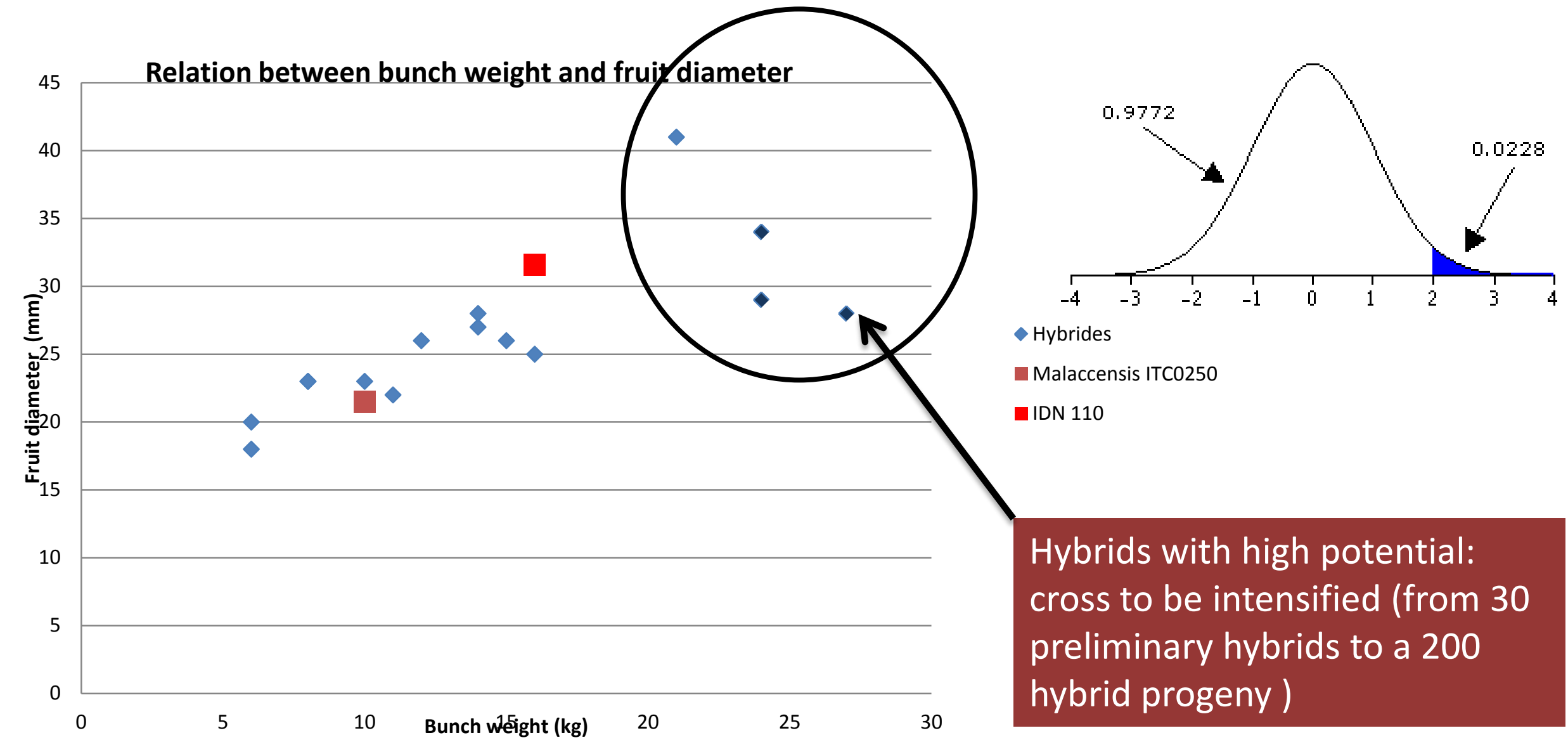

Genomics: fine tuning - research of the best allelic combinations 
Gros Michel/Cavendish:

Natural 3 ways hybrids : banksii/zebrina/malaccensis)

Proof of the concept in Guadeloupe:

First " Cavendish like » progenies relying on

Khaï (female) x Doubled-Mlalis (male) crosses

But lack of « good Khaï » accessions:

malaccensis background, combining various resistances, high gamete fertility and favorable agronomic features, ....

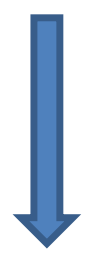

Improvement of "Khaï diploid germplasm » by continuous backcrosses and/or recurrence

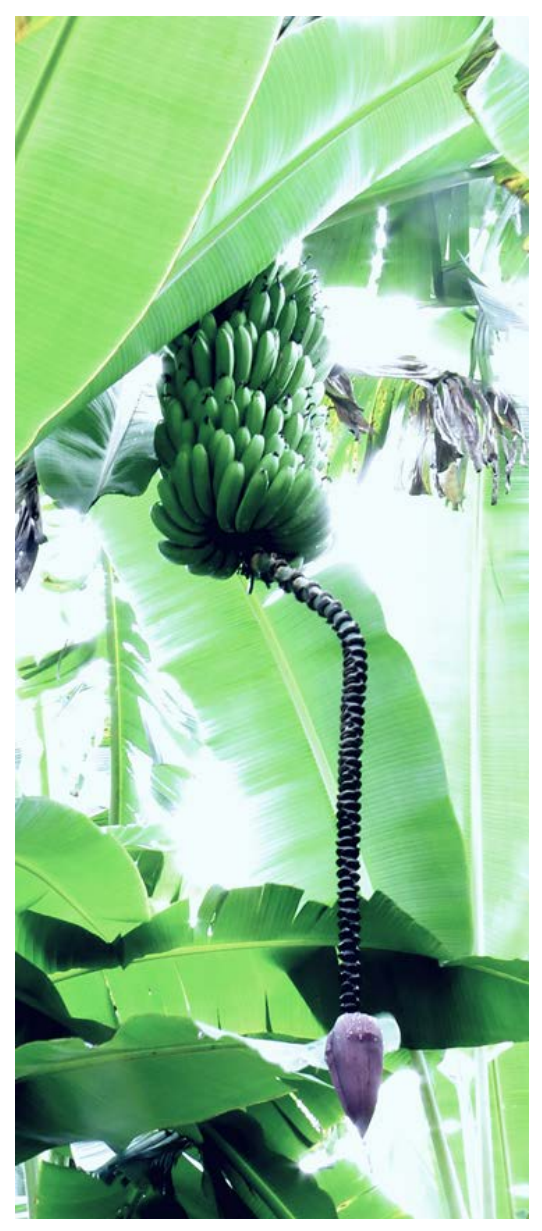

'Poyo Like' hybrid with malaccensis seedy accessions (genomic assisted selection) 


\section{$A A B$ and $A B B$ breeding}

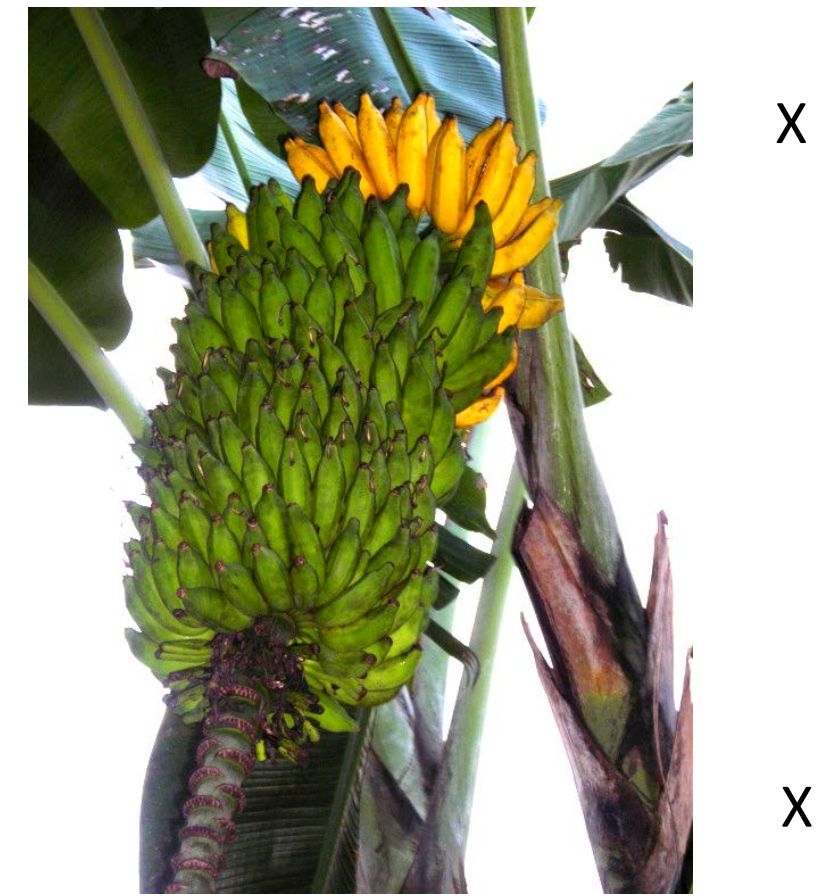

Kunnan T

AABBcv

(fertile)

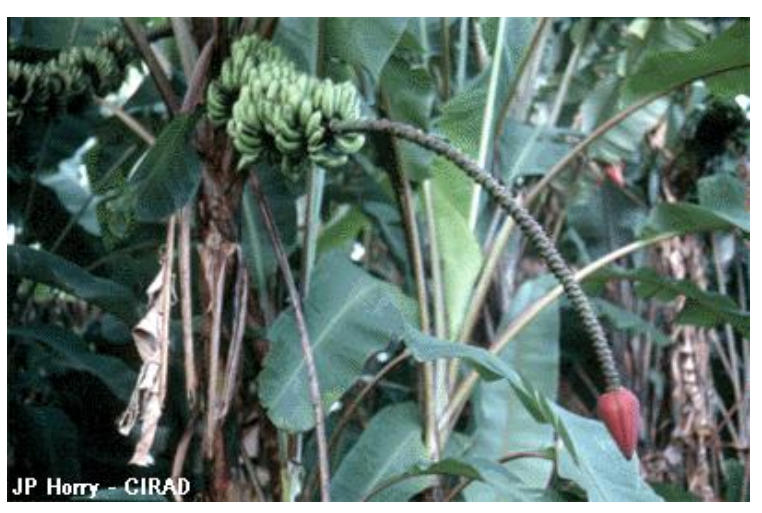

M. a. malaccensis, AAw

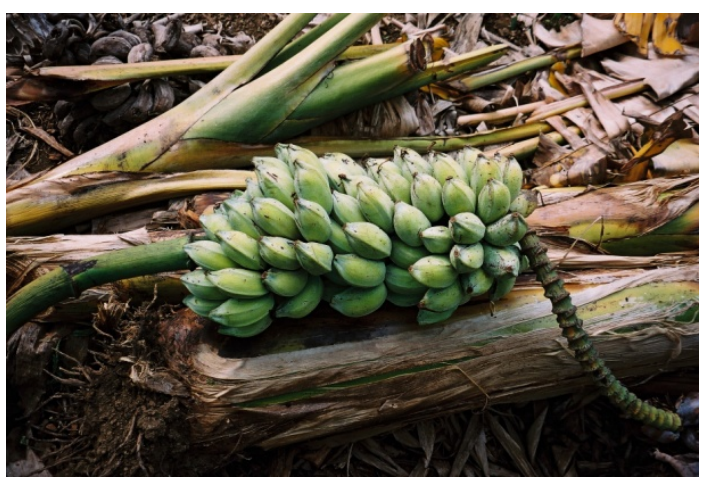

M. balbisiana, BBw

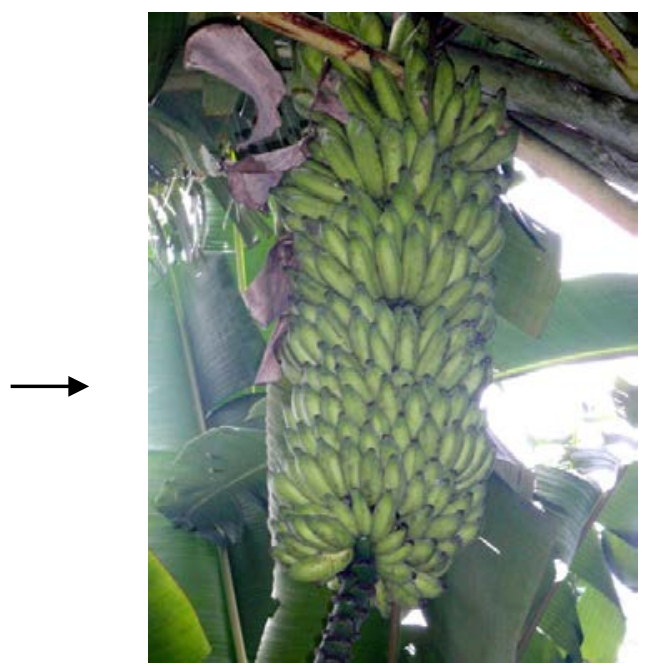

Synthetic AAB hybrid

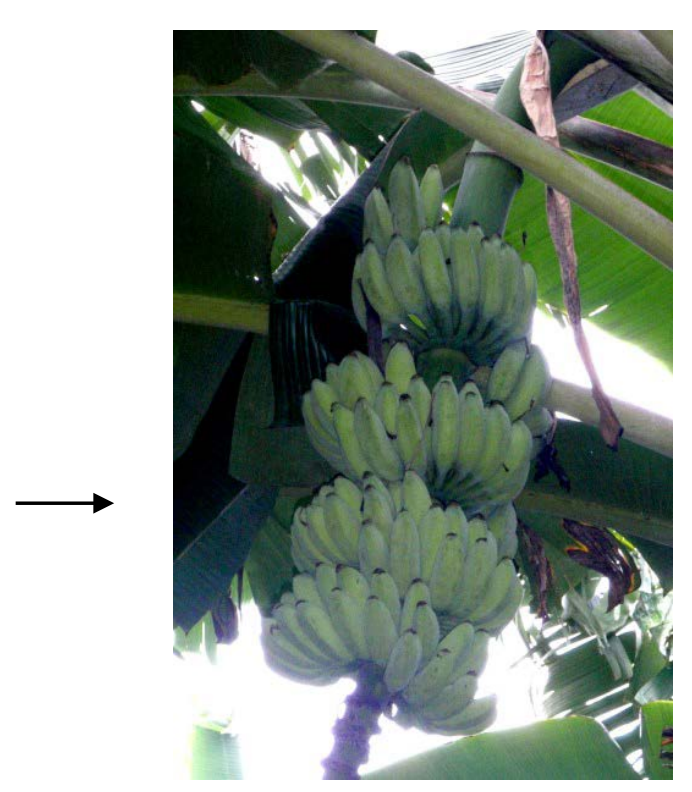

Synthetic ABB hybrid

cirad (agap 


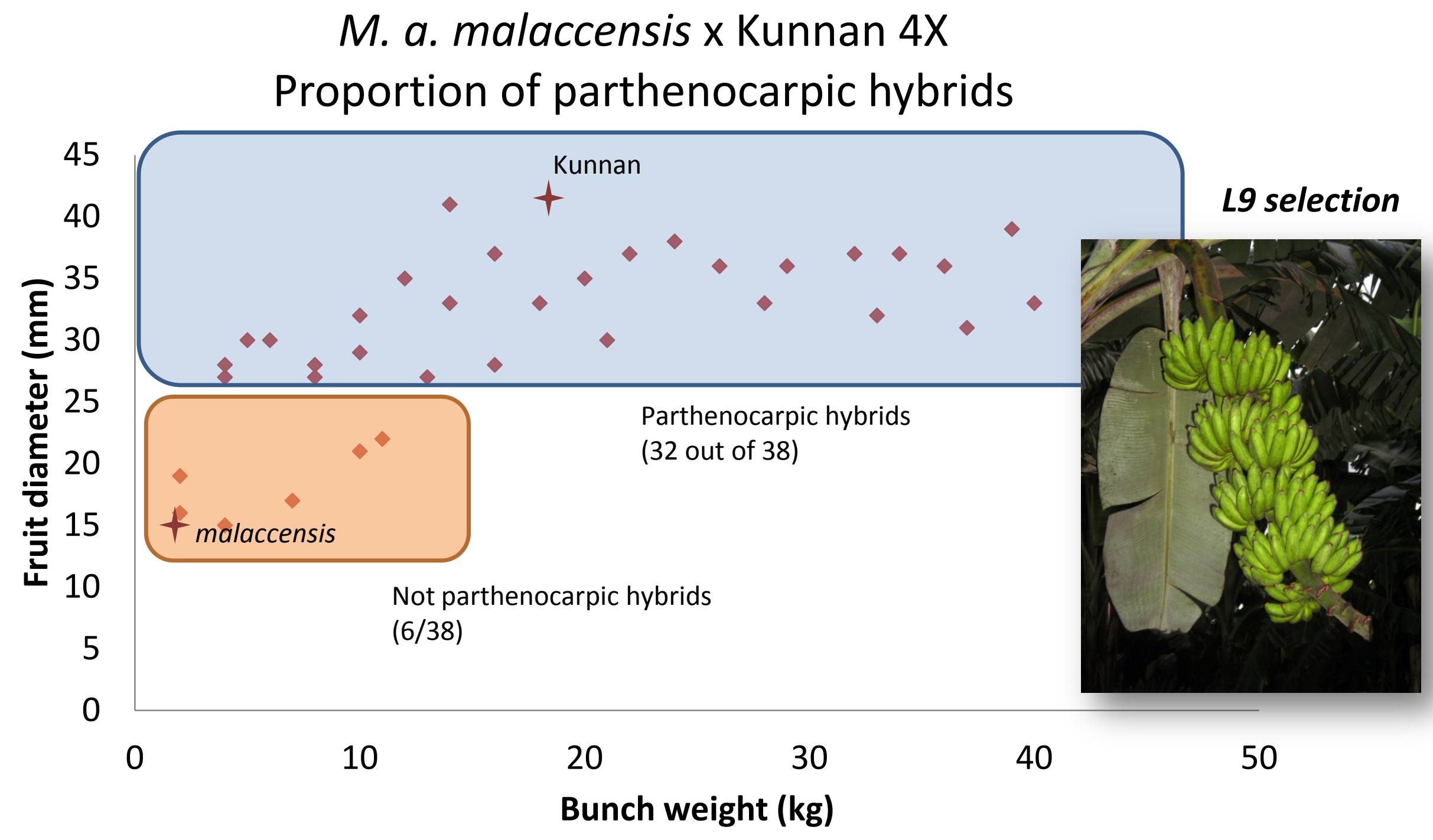

- Parthenocarpic and non-parthenocarpic hybrids

- High variability expressed for bunch weight

- Evidence for heterosis effects 


\section{Regulation of expression in interspecific hybrids}

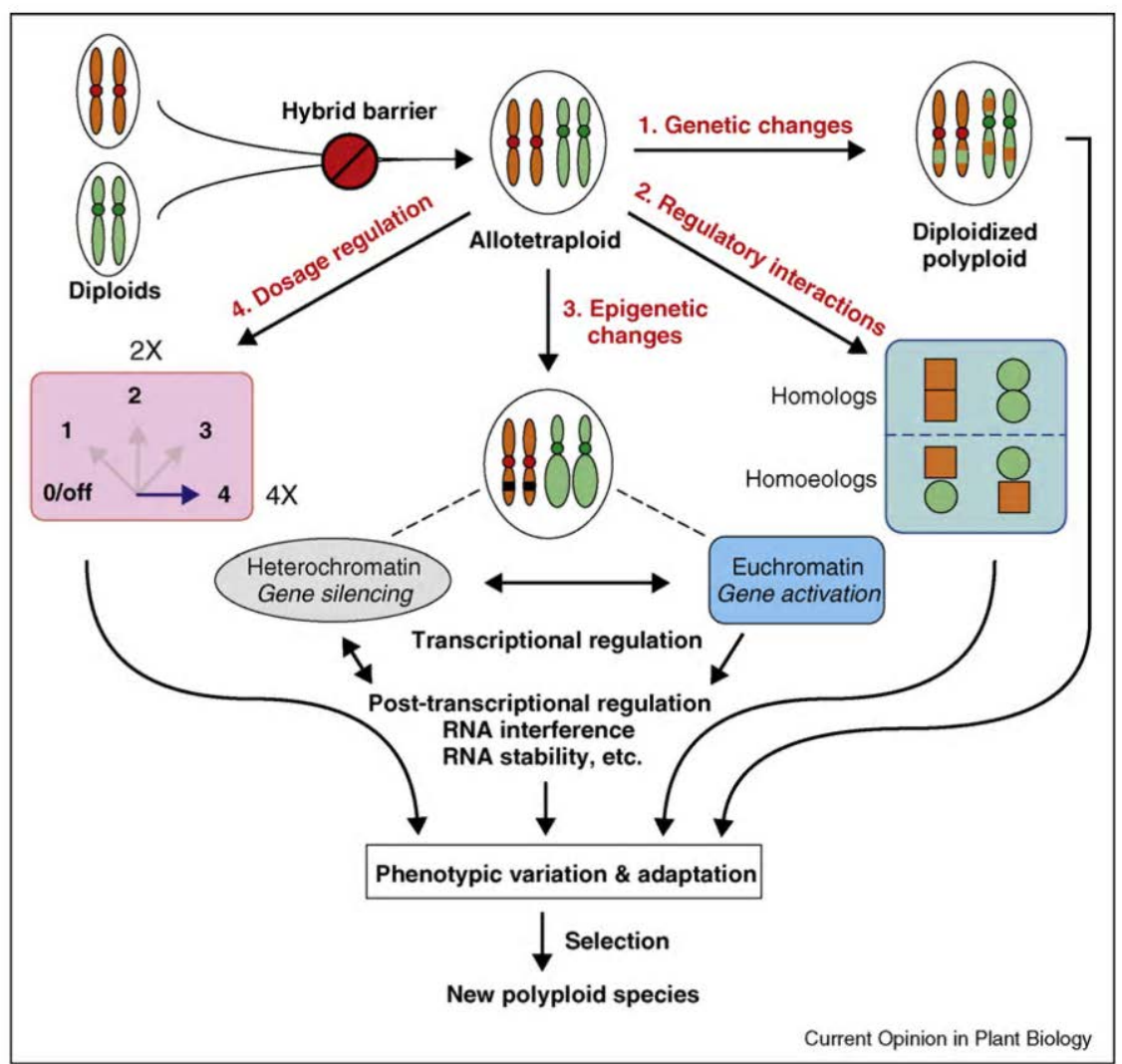

S. Jackson and Z J. Chen. Genomic and expression plasticity of polyploidy. Current Opinion in Plant Biology 2009, 13:1-7.

\section{Neo allopolyploids:}

confrontation of two differentiated and regulated genomes

a Neoregulation of gene expression

a Methylation, histones acetylation, ...

a Post transcriptionnal activities (miRNA, siRNA, ...)

a Reactivation of transposable elements $\rightarrow$ example in Musa : e-BSV 


\section{Postbreeding improvement: induced somaclonal variations, GMO's, etc...}

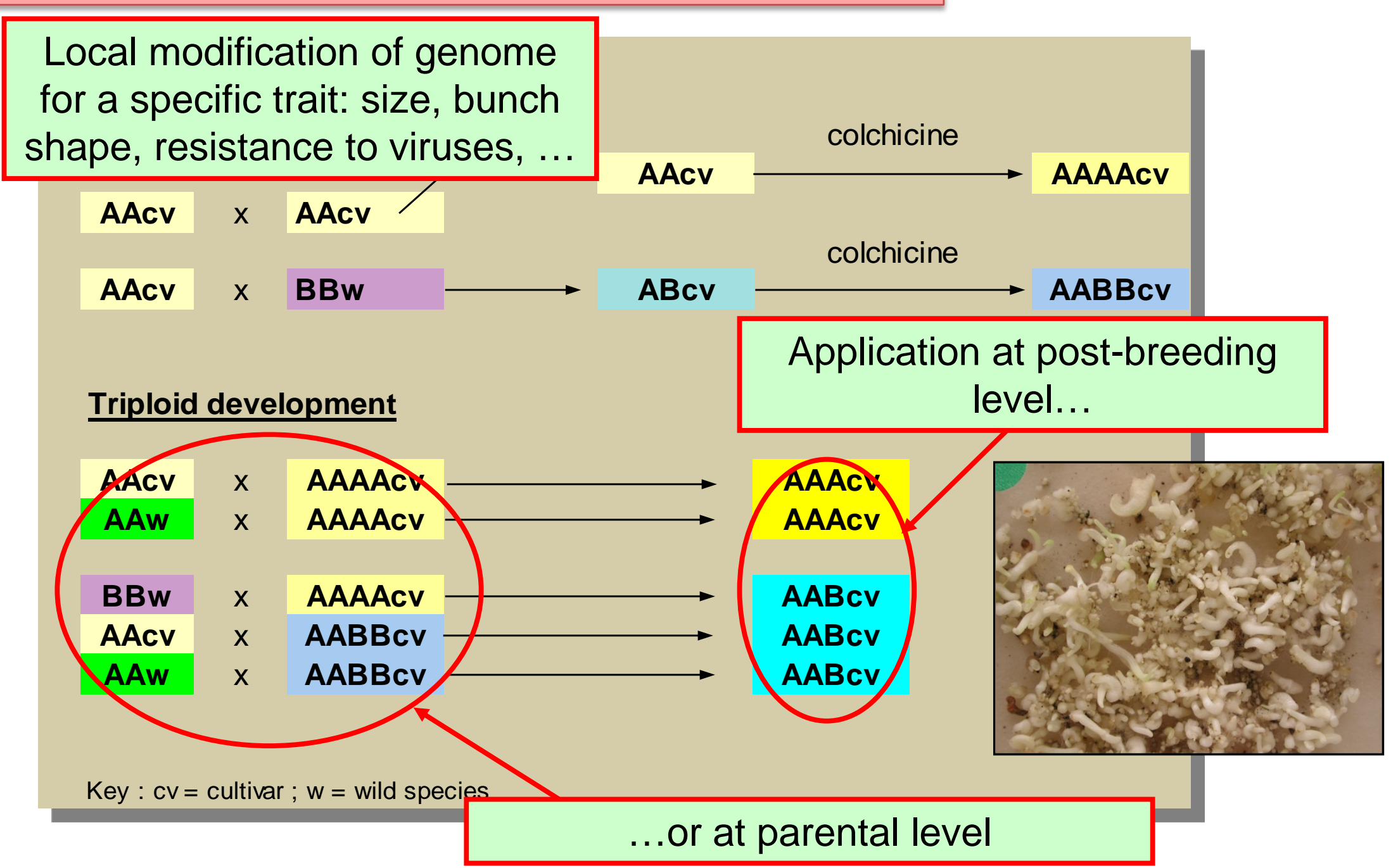




\section{Banana Breeding at CIRAD: the result of a group project}

Genetic Resources and Breeding: F. Bakry, J.P. Horry, Ch. Jenny, K. Tomekpe, F. Salmon, S. Ricci, ...

Biomathematics: X. Perrier, ...

Biomolecular Resources/Genomics: A. D’Hont, F.C. Baurens., F. Carreel, N. Yahiaoui, ....

Virology : M.L. Caruana, P.Y. Teycheney, M. Chabannes, ...

Agronomy: T. Lescot, M. Dorel, ....

Post-harvest: D. Mbeguié-A-Mbeguié, O. Gibert, D. Dufour, C. Bugaud, ...

Economy/competitivity: D. Loeillet, IT2, ...

Hybrid distribution: VITROPIC (Y. Mathieu) 


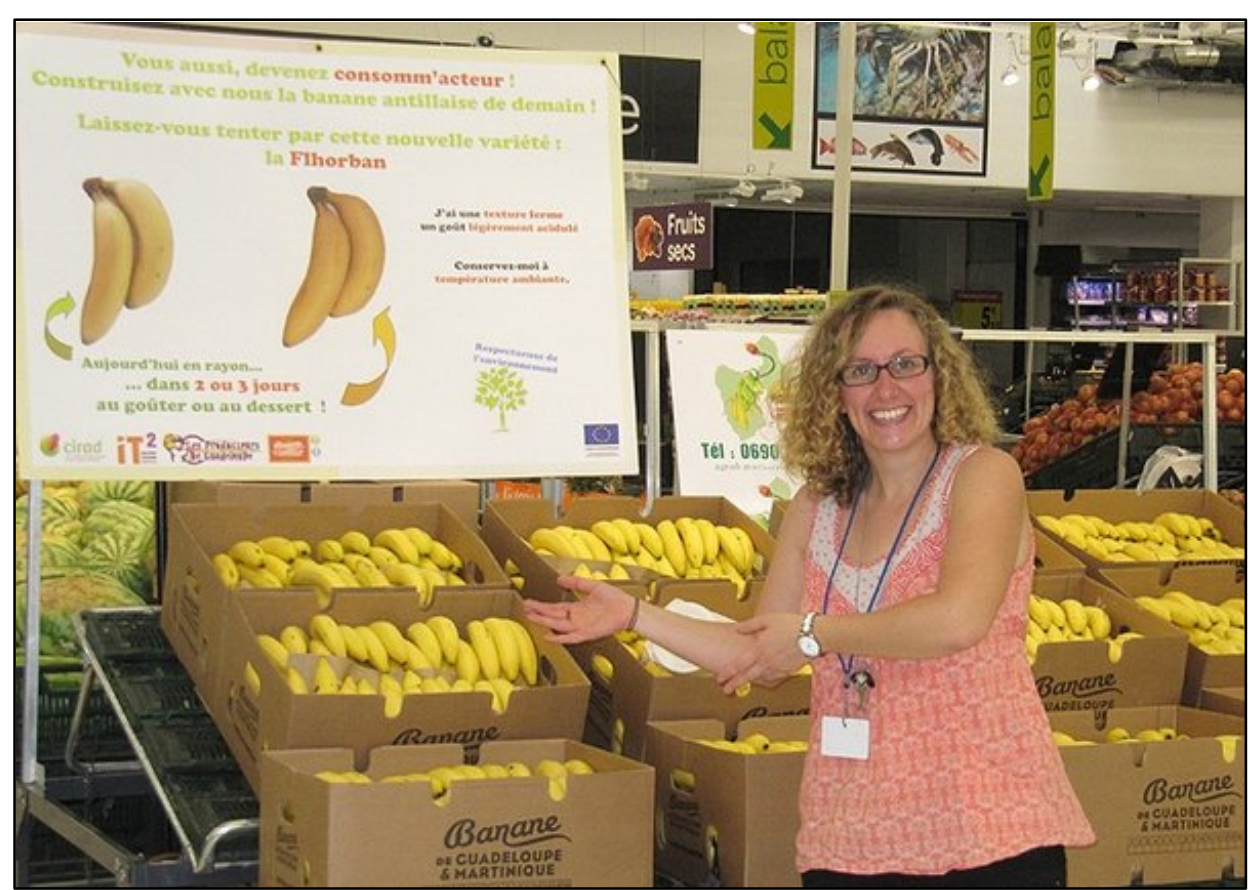

Commercialization trials of CIRAD925

Thank you for your attention

cirad (agap

\section{Acknowledgements:}

(financial support)

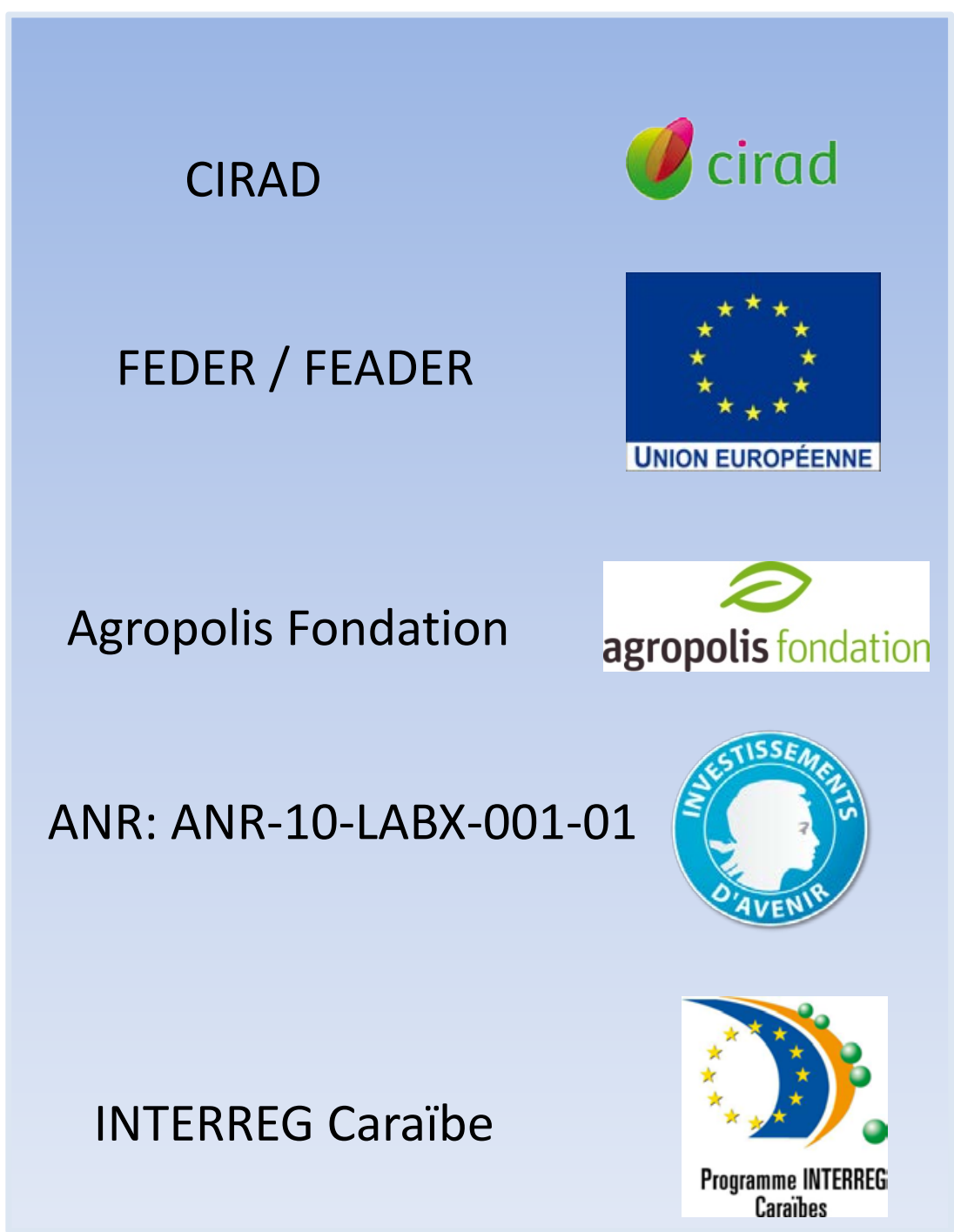

